\section{Trauma Surgery} \& Acute Care Open

\title{
Alternative strategy for the diagnosis of an enterocutaneous fistula in a resource-limited setting
}

\author{
Amber Himmler (ㄷ, 1,2,3 Maria Soledad Ordoñez Velecela, ${ }^{3}$ \\ Edison Fernando Peña Perez, ${ }^{3}$ Juan Carlos Puyana (1) , ${ }^{4}$ Juan Carlos Salamea (1) , 3,5 \\ Raul Pino Andrade (10) 3,6
}

'Department of Surgery, MedStar Georgetown University Hospital, Washington, District of Columbia, USA

${ }^{2}$ Global Surgery Fellow, University of Pittsburgh, Pittsburgh, Pennsylvania, United States

${ }^{3}$ Trauma and Acute Care Surgery, Hospital Vicente Corral Moscoso, Cuenca, Azuay, Ecuador

${ }^{4}$ Department of Surgery, University of Pittsburgh Medical Center, Pittsburgh, Pennsylvania, USA

${ }^{5}$ Universidad del Azuay Facultad de Medicina, Cuenca, Azuay, Ecuador

${ }^{6}$ Universidad de Cuenca Facultad de Medicina, Cuenca, Azuay, Ecuador

Correspondence to Dr Amber Himmler, Surgery, MedStar Georgetown University Hospital, Washignton, DC 20007, USA; amberhimmler@ gmail.com

$\mathrm{AH}$ and MSOV are joint first authors.

(C) Author(s) (or their employer(s)) 2020. Re-use permitted under CC BY-NC. No commercial re-use. See rights and permissions. Published by BMJ.

\begin{tabular}{l}
\hline To cite: \\
HimmlerA,OrdoñezVelecelaMS, \\
Peña Perez EF, et al. Trauma \\
Surg Acute Care Open \\
2020;5:e000415. \\
\hline
\end{tabular}

\section{CASE SUMMARY}

Enterocutaneous fistula (ECF) is a dreaded and challenging postoperative complication often requiring a time-consuming and multidisciplinary approach for treatment. Mortality ranges from $6 \%$ to $20 \% .^{1}$ Defined as an abnormal connection between the skin and gastrointestinal tract, ${ }^{2} \mathrm{ECF}$ occur postoperatively in $85 \%-90 \%$ of cases and spontaneously due to inflammatory bowel disease or malignancy in $5 \%-10 \%$ of cases. ${ }^{1}$ ECF are classified based on various criteria, most commonly anatomic site and quantity of the effluent. ${ }^{34} \mathrm{ECF}$ that drain less than $200 \mathrm{~mL}$ per day are classified as low output, ECF that drain more than $500 \mathrm{~mL}$ per day are classified as high output, and ECF that drain between 200 and $500 \mathrm{~mL}$ per day are classified as medium output. Generally, higher output fistulae are less likely to close spontaneously and are associated with higher overall mortality than lower-output fistulae. ${ }^{3}$ Most ECF are managed nonoperatively as up to $90 \%$ will spontaneously resolve within 5 weeks. ${ }^{4}$ Non-operative management aims to decrease the quantity effluent through proper nutritional support, in addition to sepsis control and wound management. ${ }^{3}{ }^{4}$ Strategies including the use of total parenteral nutrition, octreotide and negative pressure wound therapy have all been described in the literature. ${ }^{3}$

We present a case of a 38-year-old woman with a history of exploratory laparotomy for management of an iatrogenic uterine perforation following a dilatation and curettage who presented to the emergency department with evidence of a mediumoutput ECF. Diagnosis was confirmed with the strategy that we describe here.

\section{WHAT IS A GOOD FIRST TEST FOR THE DIAGNOSIS OF AN ECF IN A RESOURCE-LIMITED SETTING?}

A. Fistulogram.

B. Small bowel follow-through.

C. Endoscopy.

D. Plain film showing contrast on a gauze placed at the orifice of the wound after oral ingestion of contrast.

\section{WHAT WE DID AND WHY?}

D. Plain film showing contrast on a gauze placed at the orifice of the wound after oral ingestion of contrast.
Enterocutaneous fistula was suspected in this case based on the patient's presenting symptoms. However, limited radiographic capabilities and personnel would delay definitive diagnosis beyond what was deemed acceptable by the primary team. As such, we have developed a technique wherein the patient ingests $20 \mathrm{~mL}$ of water-soluble contrast medium such as gastrograffin diluted in $500 \mathrm{~mL}$ of water over a period of $30 \mathrm{~min}$. A $4 \times 4$ gauze is placed over the cutaneous opening. After 6 hours, the gauze is removed, and a plain X-ray is performed of only the gauze. If radio-opaque, as in this case (figure 1), the diagnosis of ECF is confirmed and appropriate management is initiated. If the diagnosis is not confirmed but clinical suspicion remains high, further, more time-consuming studies can be pursued.

Although clinical data can offer clues to the diagnosis based on the patient's history and the quality and quantity of the effluent on physical examination, radiologic confirmation of the diagnosis is often necessary. ${ }^{2}$ A fistulogram, which

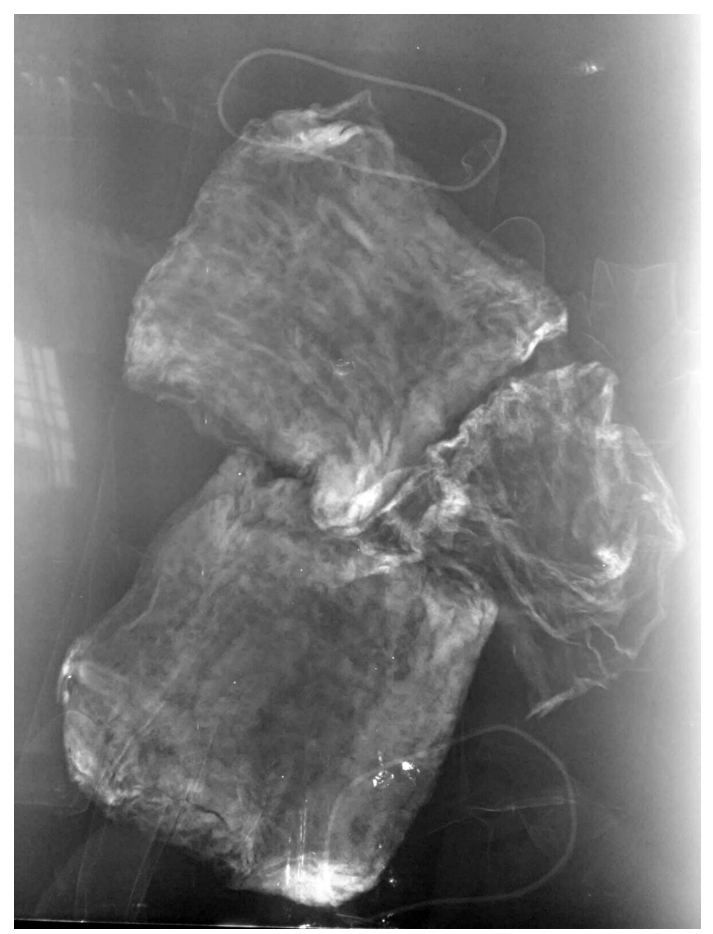

Figure 1 A $4 \times 4$ gauze which was placed over the cutaneous opening of a suspected enterocutaneous fistula appears radio-opaque on X-ray, confirming the diagnosis of an enterocutaneous fistula. 
is often the first study ordered in these cases, is performed injecting contrast into the cutaneous opening using a pediatric feeding tube, angiocatheter, or nasogastric tube, followed by a spot radiograph or fluoroscopic examination. Although overall a safe procedure, injuries to the small bowel and pseudocyst rupture have been reported. Small bowel follow-through is the gold standard for patients with complicated intraluminal pathologies such as Crohn's disease. This procedure, however, can be particularly onerous for the patient, requiring the ingestion of 500-600 mL of contrast and several hours with repeated radiographs. More complex presentations may require CT scan or MRI for characterization of abscess, obstruction, inflammation, or other non-contiguous lesions that prevent a fistula from healing. ${ }^{2}$

The strategy described here can be easily performed in resource-limited settings to confirm the diagnosis of ECF. Although it does not provide precise anatomic information that would be needed for intraoperative repair, it does allow for appropriate management to be initiated in a timely fashion. It also allows for confirmation of small ECF that do not permit canalization for contrast injection for a fistulogram. This method negates the need for a radiologist to make the diagnosis. Staff does not have to transport the patient to radiology, often critical in units with high nurse:patient ratios. It also reduces the radiation to which a patient is exposed. Moreover, in settings with few X-ray machines and limited fluoroscopic ability, this technique allows for less time-consuming use of these resources.

This simple technique can be useful in the expeditious confirmation of the diagnosis of an ECF in a setting with limited resources. To our knowledge, this is the first description of this technique in the literature.
Contributors AH: Surgical Resident, participating in a Global Surgery research year in Cuenca, Ecuador. Contribution: article writing. MSOV: Surgical Resident. Contribution: article writing. EFPP: Surgical Resident: Contribution: article writing. JCS: Chief of the Trauma and Acute Care Surgery service at Hospital Vicente Corral Moscosso (HVCM). Contribution: review of article. JCP: Trauma and Acute Care Surgery Attending at UPMC. Contribution: review of article. RPA: Trauma and Acute Care Surgery Attending at HVCM. Contribution: technique and protocol developed by this attending.

Funding The authors have not declared a specific grant for this research from any funding agency in the public, commercial or not-for-profit sectors.

Competing interests None declared.

Patient consent for publication Not required.

Provenance and peer review Not commissioned; externally peer reviewed.

Open access This is an open access article distributed in accordance with the Creative Commons Attribution Non Commercial (CC BY-NC 4.0) license, which permits others to distribute, remix, adapt, build upon this work non-commercially, and license their derivative works on different terms, provided the original work is properly cited, appropriate credit is given, any changes made indicated, and the use is non-commercial. See: http://creativecommons.org/licenses/by-nc/4.0/.

\section{ORCID iDs}

Amber Himmler http://orcid.org/0000-0001-7180-5787

Juan Carlos Puyana http://orcid.org/0000-0003-4284-4693

Juan Carlos Salamea http://orcid.org/0000-0002-9084-3030

Raul Pino Andrade http://orcid.org/0000-0002-0294-5468

\section{REFERENCES}

1. Osborn C, Fischer JE. How I do it: gastrointestinal cutaneous fistulas. J Gastrointest Surg 2009;13:2068-73.

2. Lee JK, Stein SL. Radiographic and endoscopic diagnosis and treatment of enterocutaneous fistulas. Clin Colon Rectal Surg 2010;23:149-60.

3. Kugler NW, Boateng S, Webb TP, Trevino CM. Enteric fistula treatment and management: results of an institutional inpatient treatment protocol. WMJ 2019;118:75-9.

4. Cowen K, Cassaro S. Fistula, enterocutaneous. StatPearls. Treasure Island, FL, USA: StatPearls Publishing LLC, 2019. 